RODRIGUES, Léo Peixoto; NEVES, Fabrício Monteiro. A sociologia de Niklas Luhmann. Petrópolis: Vozes, 2017, 189p.

\author{
Éverton Garcia da Costa \\ Gabriel Bandeira Coelho
}

\section{PARA ENTENDER A SOCIOLOGIA DE NIKLAS LUHMANN}

Reza a lenda que, pouco antes de sua nomeação para o cargo de professor de sociologia na Universidade de Bielefeld, Luhmann foi indagado sobre qual objeto de pesquisa desejaria trabalhar. Sua resposta teria sido: a teoria da sociedade moderna, duração 30 anos, sem custos. Luhmann cumpriu criteriosamente essa promessa. Desde o momento em que ingressou na Faculdade de Sociologia da Universidade de Bielefeld, em 1969, até o momento de sua aposentadoria, em 1993, o sociólogo alemão construiu uma ampla e complexa arquitetura conceitual, por meio da qual investigou as diferentes esferas da sociedade moderna - o direito, a arte, a ciência, a política, a religião, a moral etc. A obra luhmanniana é vasta: composta por mais de 60 livros, mais de 400 artigos, o que representa cerca de 14 mil páginas publicadas. Não é exagero afirmar, com efeito, que Luhmann é um dos pensadores sociais mais proeminentes da segunda metade do século XX e o sociólogo alemão mais importante, desde Weber.

Luhmann é um pensador com ideias muito controversas. Defende, por exemplo, que a sociologia enfrenta uma grave crise teórica, uma vez que tanto a literatura especializada como as reuniões acadêmicas realizadas na área ao redor do mundo têm como referên- cia fundamental os clássicos da disciplina: Marx, Weber, Simmel e Durkheim. A impressão que fica, defende o autor, é a de que a teia conceitual da sociologia se esgotou com os clássicos.

É importante ressaltar, no entanto, que Luhmann não nega a importância e as contribuições teóricas dos clássicos para a sociologia. Pelo contrário: defende que eles, ainda hoje, disponibilizam algumas teorias de médio alcance, principalmente para o uso na pesquisa empírica. Todavia, a seu ver, não há, nos clássicos, uma descrição teórica coerente com a complexidade característica da sociedade contemporânea. Para Luhmann, tal sociedade só pode ser descrita de forma realmente coerente por meio de um novo modelo teórico, geral, dotado de elementos conceituais capazes de explicar o funcionamento dos diferentes sistemas sociais (política, economia, direito, arte, ciência etc.).

A controvérsia em torno da obra de Luhmann também está relacionada ao fato de que o autor se apropria de conceitos e ideias oriundos de outras áreas do conhecimento como a biologia, a cibernética, a matemática, a física, dentre outras - na sua tentativa de explicar o social. A própria noção de autopoiésis, por exemplo, utilizada pelo autor para caracterizar os sistemas sociais, foi desenvolvida pelo biólogo chileno Humberto Maturana. Por esse motivo, Luhmann tem sido acusado, injustamente, de ser um pensador "positivista".

No entanto, o ponto mais controverso e polêmico na obra de Luhmann, sem dúvida, é o seu conhecido argumento de que a sociedade não é constituída por seres humanos - como tem defendido a tradição teórica das ciências sociais -, mas, antes, por comunicações. Para o 1 Ao contrário do que prega o positivismo, ou seja, que há, no mundo, uma realidade comum e objetiva, a qual pode ser apreendida (para não dizer traduzida) através do método observacional, a teoria luhmanniana não busca ser o reflexo total da realidade do objeto, tampouco pretende esgotar todas as possibilidades de conhecimento desse objeto. Luhmann sabe que sua teoria - cuja matriz epistemológica é o construtivismo - constitui, antes de tudo, um modelo teórico contingente, que apresenta uma descrição parcial do social, e que não busca competir, em momento algum, com outros empreendimentos teóricos. 
autor, os seres humanos não estão no centro da sociedade, mas sim no seu entorno. Com esse deslocamento teórico na concepção do homem, Luhmann rompe não apenas com a tradição sociológica, mas, sobretudo, com a própria tradição antropocêntrica do Iluminismo europeu. Vale lembrar, que, na Metafísica dos Costumes, por exemplo, Kant defendeu que o homem não deve ser nunca tomado como meio, mas sempre como fim. Luhmann vai ao encontro da tese kantiana ao sustentar que os seres humanos são o meio através do qual os sistemas sociais se reproduzem. Por sustentar esse argumento, o sociólogo de Bielefeld tem sido rotulado como um pensador "anti-humanista". ${ }^{2}$

Por defender ideias polêmicas como essas, ou seja, que a sociologia estagnou nos clássicos, que a sociedade não é composta por homens, e também por se apropriar de conceitos oriundos de áreas como a biologia e a cibernética para explicar o social, Luhmann é um dos mais controversos autores do campo da teoria sociológica, e uma persona non grata em alguns campos ideológicos.

Há, com efeito, uma grande resistência, em alguns nichos ideológicos, em aceitar as ideias de Luhmann - as quais, diga-se de passagem, são dotadas de uma riqueza teórica e epistemológica e de um ineditismo ímpar nas ciências humanas. O Brasil é um claro exemثิ plo disso. Embora alguns dos principais livros Фं de Luhmann tenham sido publicados desde o final da década de 1980 e ao longo dos anos क 1990, são raros os que foram traduzidos para o português.

Uma iniciativa adotada pela Editora $\stackrel{i}{i}$ Vozes tem buscado, justamente, alterar essa

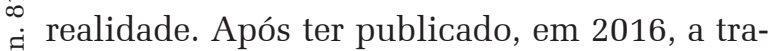
हे dução de Sistemas Sociais: esboço para uma $\vec{t}$ teoria geral, uma das obras mais importantes

${ }^{2}$ Deve ficar claro que Luhmann, em nenhum momento da II sua vasta obra, alegou que os seres humanos não são imo portantes, ou então que devam ser usados como meio para se alcançar um determinado objetivo. Ao tratá-los como entorno da sociedade, o sociólogo alemão apenas buscou traçar uma descrição teórica do social, livre de qualquer tipo de determinação psicológica. de Luhmann, ${ }^{3}$ a editora lançou, em 2017, A sociologia de Niklas Luhmann, livro escrito por Léo Peixoto Rodrigues e Fabrício Monteiro Neves, dois dos principais especialistas brasileiros em teoria luhmanniana. ${ }^{4}$

O livro assinado por Rodrigues e Neves é de grande importância para a disseminação das ideias de Luhmann no clima intelectual brasileiro. Os autores conseguiram sintetizar, em apenas 189 páginas, o denso pensamento de Luhmann, apresentando, de forma simples e didática, sem perder o rigor teórico, os principais conceitos que constituem a teoria do sociólogo alemão. Um ponto importante a ressaltar, nessa obra, diz respeito ao aspecto interdisciplinar da teoria luhmanniana ressaltada pelos autores. Para eles, Luhmann conhece, discute e, em muitos casos, ressemantiza os conceitos das áreas da Biologia, da Física, da Psicologia, da Economia, da Teoria da Comunicação, da Teoria do Conhecimento, da Cibernética e da Filosofia no que concerne à explicação dos fenômenos sociais. Segundo Rodrigues e Neves (p. 17-8), "Luhmann ousou transpor estas barreiras disciplinares e desenvolver um conhecimento científico verdadeiramente transdisciplinar", refundando, assim, os pressupostos epistemológicos de toda uma Teoria do Conhecimento para as ciências humanas, a partir da noção de sistema autopoiético.

A sociologia de Niklas Luhmann é um

3 Obra que "renova e refunda as bases epistemológicas para uma metateoria da sociedade, como um sistema que se auto-observa" (p. 16)

${ }^{4}$ A sociologia de Niklas Luhmann faz parte da coleção "Sociologia: pontos de referência”. Nessa coleção, a Editora Vozes tem apresentado o pensamento de alguns dos mais proeminentes sociólogos da história. A Vozes, a partir dessa singular coleção, demarca um importante espaço, no que diz respeito às publicações no âmbito da Sociologia brasileira, contribuindo significativamente para as pesquisas na área de teoria e de epistemologia no país. Além da obra de Rodrigues e Neves sobre a sociologia luhmanniana, outros livros de renomados autores internacionais destacam-se na referida coleção, quais sejam: A sociologia como ciência, de Raymond Boudon; A sociologia de Marx, de Jean-Pierre Durand; A sociologia de Durkheim, de Philippe Steiner; A sociologia de Erving Goffman, de Jean Nizet e Natalie Rigaux; A sociologia de Anthony Giddens, de Jean Nizet; A sociologia de Max Weber, de Catherine Colliot-Thèléne; História da sociologia 1 - Antes de 1918, de Charles-Henry Cuin e François Gresle; História da sociologia 2 Depois de 1918, de Charles-Henry Cuin e François Gresle; e A teoria de Pierre Bourdieu e seus usos sociológicos, de Anne Jourdain e Sidonie Naulin. 
livro voltado para aqueles pesquisadores que almejam ter um primeiro contato com a obra de Luhmann, que buscam conhecer suas principais ideias, conceitos, influências, e os autores com os quais dialoga. Trata-se de uma obra importante, que atende criteriosamente os objetivos aos quais se propõe. Como salientam os autores, a ideia de escrever um livro sobre a teoria sistêmica luhmanniana teve duas motivações principais: primeiro, transformar uma teoria amplamente abstrata e rebuscada em algo acessível para quem deseja compreendê-la. "O outro motivo deveu-se à escassez de material escrito em português sobre o autor, ou traduções de suas principais obras até então” (p. 20).

Por fim, é importante frisar que os autores chamam a atenção para o fato de que não estava entre seus objetivos apresentar a historização e as transformações do conceito de sistema, aplicado à física, à cibernética e à biologia, tampouco "fazer uma exposição mais demorada da trajetória do pensamento luhmanniano até a adoção do conceito de autopoiésis, desenvolvido pela biologia” ( $p$. 22). Antes disso, seu objetivo principal era introduzir o leitor no vasto universo teórico de Luhmnann, apresentando e discutindo seus principais conceitos, tais como sistema, autopoiéses, sentido, comunicação, sistema social, evolução, dentre outros, trazendo ainda alguns tópicos epistemológicos nos quais se comparam as ideias de Luhmann à tradição teórica da sociologia.

Recebido para públicação em 19 de junho de 2017 Aceito em 07 de agosto de 2017

Everton Garcia da Costa - Licenciado em Letras e Mestre em Ciências Sociais (UFPel). Doutorando em Sociologia (UFRGS). Integrante do Grupo de Estudos Sobre Universidade (GEU Sociologia\UFRGS). eve.garcia.costa@gmail.com

Gabriel Bandeira Coelho - Doutorando em Sociologia pela Universidade Federal do Rio Grande do Sul (UFRGS). Mestre em Sociologia pela Universidade Federal de Pelotas (UFPel). Integra o Núcleo (grupo) de Pesquisa TEMAS, desenvolvendo pesquisas na área de Sociologia da Ciência, sobretudo em relação à interdisciplinaridade na área de Ciências Ambientais. gabrielbandeiracoelho@yahoo.com.br 
